\title{
Short Papers
}

\author{
Induction Motor Bearing Failure Detection \\ and Diagnosis: Park and Concordia Transform \\ Approaches Comparative Study
}

Izzet Yilmaz Önel and Mohamed El Hachemi Benbouzid

\begin{abstract}
This paper deals with the problem of bearing failure detection and diagnosis in induction motors. Indeed, bearing deterioration is now the main cause of induction motor rotor failures. In this context, two fault detection and diagnosis techniques, namely the Park transform approach and the Concordia transform, are briefly presented and compared. Experimental tests, on a $0.75 \mathrm{~kW}$ two-pole induction motor with artificial bearing damage, outline the main features of the aforementioned approaches for small- and medium-size induction motors bearing failure detection and/or diagnosis.
\end{abstract}

Index Terms-Bearing failure, Concordia transform, diagnosis, fault detection, induction motor, Park transform.

\section{INTRODUCTION}

Rotor failures now account for a larger percentage of total induction motor failures [1]. Bearing deterioration is now the main cause of rotor failures.

\section{A. Bearing Failures}

The main factors behind bearing faults are dust and corrosion. Induction motors are often operated in hard conditions. That is why foreign materials, water, acid, and humidity are the main reasons for bearing deteriorations. Contamination and corrosion frequently accelerate bearing failures because of the harsh environments present in most industrial settings. Dirt and other foreign matters that are commonly present often contaminate the bearing lubrication. The abrasive nature of these minute particles, whose hardness can vary from relatively soft to diamond-like, causes pitting and sanding that lead to measurable wear of the balls and raceways. Bearing corrosion is produced by the presence of water, acids, deteriorated lubrication, and even perspiration from careless handling during installation. Once, the chemical reaction has advanced sufficiently, particles are worn off resulting in the same abrasive effect produced by bearing contamination. Improper lubrication includes both under and overlubrication.

In either case, the rolling elements are unable to rotate on the designed oil film causing increased levels of heating. This excessive heating causes the grease to break down, which reduces its ability to lubricate the bearing elements and accelerates the failure process [2].

Bearing problems are also caused by improperly forcing the bearing onto the shaft or into the housing. This produces physical damage

Manuscript received March 2, 2007; revised October 7, 2007. Recommended by Technical Editor M.-C. Tsai.

I. Y. Önel was with the Electrical Engineering Department, Electrical and Electronics Faculty, Yildiz Technical University (YTU), Istanbul 34349, Turkey. He is now with Yay Enerji, Serenlikuyu Mevkii Muallimköy, 41400 Gebze, Turkey (e-mail: izzet.onel@yaylagrup.com).

M. E. H. Benbouzid is with the Laboratoire Brestois de Mécanique et des Systèmes (LBMS), University of Western Brittany, Brest 29238, France (e-mail: m.benbouzid@ieee.org).

Color versions of one or more of the figures in this paper are available online at http://ieeexplore.ieee.org.

Digital Object Identifier 10.1109/TMECH.2008.918535

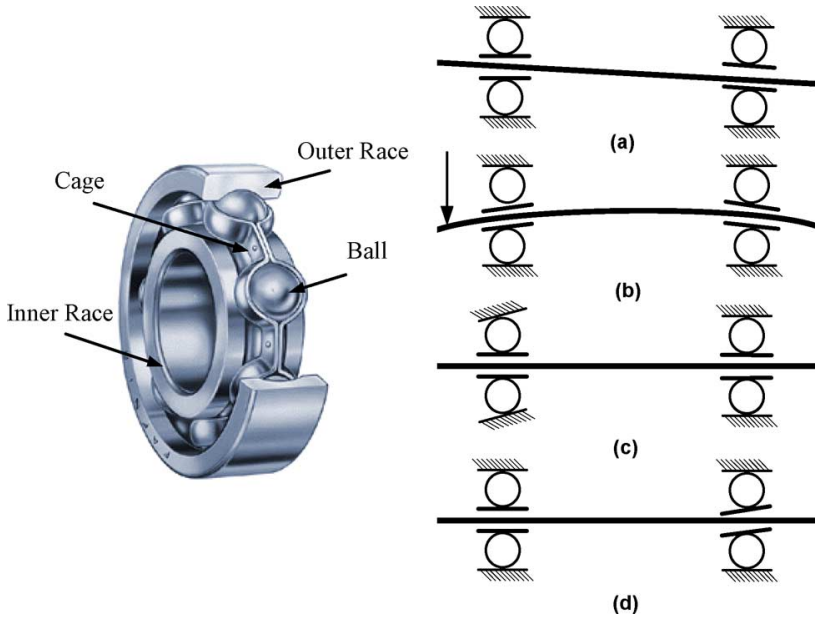

Fig. 1. (a) Misalignment (out-of-line). (b) Shaft deflection. (c) Cocked or tilted outer race. (d) Cocked or tilted inner race.

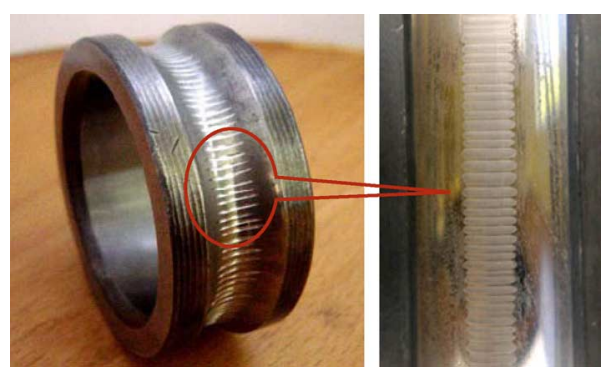

Fig. 2. Bearing fluting.

in the form of brinelling or false brinelling of the raceways, which leads to premature failure. Misalignment of the bearing, which occurs in four ways depicted in Fig. 1, is also a common result of defective bearing installation. In a small fraction of induction motor applications, bearings prematurely fail due to electrical causes. Currents flowing through induction motor bearings have the potential to create premature failure of these bearings. Fig. 2 shows the typical fluting pattern in a bearing race due to metallurgical damage from interrupted electrical current flow. Increased noise and vibration are typical symptoms of bearing damage for a bearing such as this. Over time, lubrication fatigue and mechanical wear lead to ultimate bearing failure [3].

\section{B. State of the Art}

There are many condition monitoring methods used for the detection and the diagnosis of bearing failure: vibration measurements, temperature measurement, the shock pulse method (SPM), and acoustic emission (AE)

Among these, vibration measurements are most widely used [4]. A detailed review of different vibration and acoustic methods, such as vibration measurements in time and frequency domains, sound measurement, the SPM, and the AE technique for condition monitoring of bearing failure is given in [5]-[7]. In fact, large induction motors are often equipped with mechanical sensors, which are primarily vibration sensors such as proximity probes. However, these are delicate and 
expensive. Moreover, it is not economically or physically feasible to provide the same for smaller induction motors.

Owing to the infeasibility of these traditional techniques because of the economical constraints in small- and medium-size induction motors, stator current harmonic measurement is appearing as an alternative to the vibration measurement methods. Indeed, various researchers have suggested that stator current monitoring can provide the same indications without requiring access to the motor. This technique utilizes the results of spectral analysis of the stator current or supply current of an induction motor for the diagnosis. Indeed, the characteristic frequencies of bearing damage are often used to monitor certain frequency components [8]-[18]. Example techniques that have been applied to characteristic fault frequency detection include frequency-domain analysis [9]-[12], statistical methods [13], spectral models [14], wavelets [15]-[17], artificial neural networks [15], [18], and fuzzy logic [19].

When the available literature on induction motor fault detection and diagnosis is scanned, some of the applied techniques are found to be based on the processing of the stator current pattern. These techniques are based on Park transform or Concordia transform. The global applicability of the Park approach has been demonstrated in [20]-[22] for induction motor stator faults and in [23] for bearing failures. The Concordia approach has also been successfully applied for the detection and the diagnosis of stator faults in [24] and faults in a pulse width modulation (PWM) inverter feeding an induction motor in [25]. The originality of these fault detection and diagnosis techniques relyon the stator current well processing. In this case, there is no need for any particular or advanced processing technique.

The main objective of this paper is to provide a comparison between the Park and the Concordia transforms as fault detection and diagnosis approaches in the particular case of bearing failures. This comparison should be useful for potential users of these pattern-based techniques as Park and Concordia transforms are often mingled [24].

\section{PARK TRANSFORM VERSUS CONCORDIA TRANSFORM}

A two-dimensional representation can be used for describing threephase induction motor phenomena. A suitable one is based on the stator current Park vector. Park transform reduces the number of current components and makes the calculation easier.

In a three-phase induction motor, stator current has three $(a, b, c)$ components. When Concordia transform is applied to the mains, $s D$ and $s Q$ components of the stator current are obtained. This transform is governed by (1):

$$
\left\{\begin{array}{l}
I_{s D}=\sqrt{\frac{2}{3}} I_{a}-\frac{1}{\sqrt{6}} I_{b}-\frac{1}{\sqrt{6}} I_{c} \\
I_{s Q}=\frac{1}{\sqrt{2}} I_{b}-\frac{1}{\sqrt{2}} I_{c}
\end{array} .\right.
$$

These components are stationary according to the stator.

If Park transform (2) is applied to the $s D-s Q$ system, $D$ and $Q$ components are obtained:

$$
\left[\begin{array}{c}
I_{D} \\
I_{Q}
\end{array}\right]=\left[\begin{array}{cc}
\cos \theta_{r} & \sin \theta_{r} \\
-\sin \theta_{r} & \cos \theta_{r}
\end{array}\right]\left[\begin{array}{c}
I_{s D} \\
I_{S Q}
\end{array}\right]
$$

These components are stationary according to the rotor. Fig. 3 summarizes the aforementioned transforms where $I_{s}$ is the stator current vector that rotates at the angular frequency $\omega_{s}$.

Transforming the $a b c$ system to the $s D-s Q$ system is very simple. Park transform is more complicated than Concordia's. Indeed, rotor

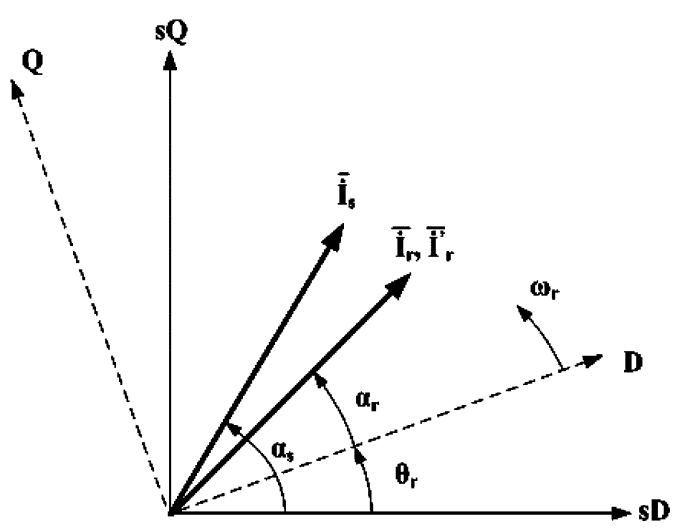

Fig. 3. Representation of $s D-s Q$ and $D-Q$ axes.

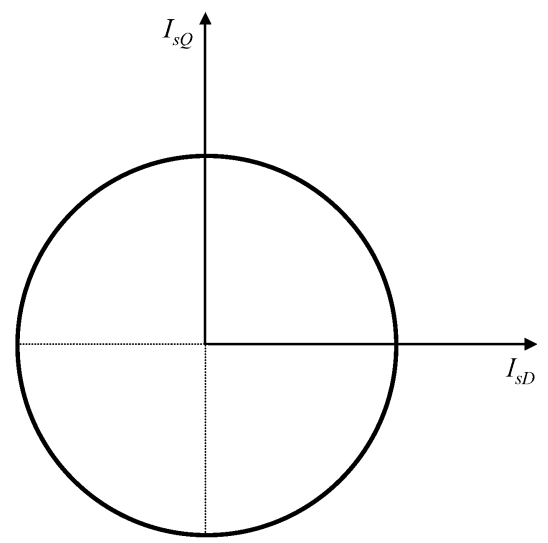

(a)

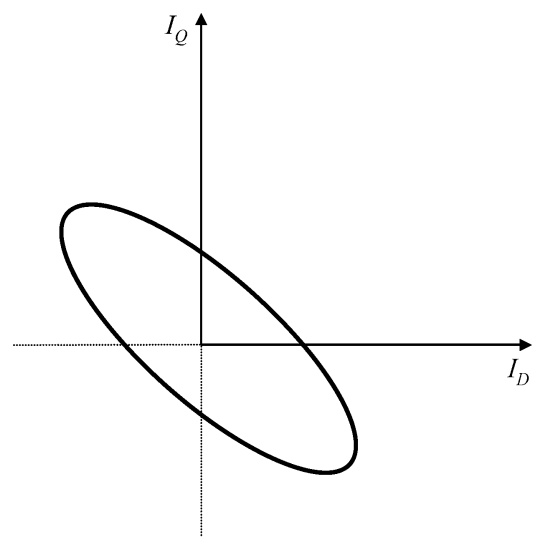

(b)

Fig. 4. Current patterns for ideal conditions. (a) Concordia transform. (b) New Park transform.

speed or position must be known. But stator current $D$ and $Q$ components have valuable information for bearing fault detection. Indeed, they contain the speed information that is obviously affected by the bearing condition.

Using this new Park transform, the obtained $D$ and $Q$ current trajectory is not a circle, as is the case for the $s D$ and $s Q$ current trajectory. It is an ellipse as schematically depicted by Fig. 4 . It is also a simple reference figure that allows the detection of abnormal conditions by monitoring the deviations of acquired patterns. 

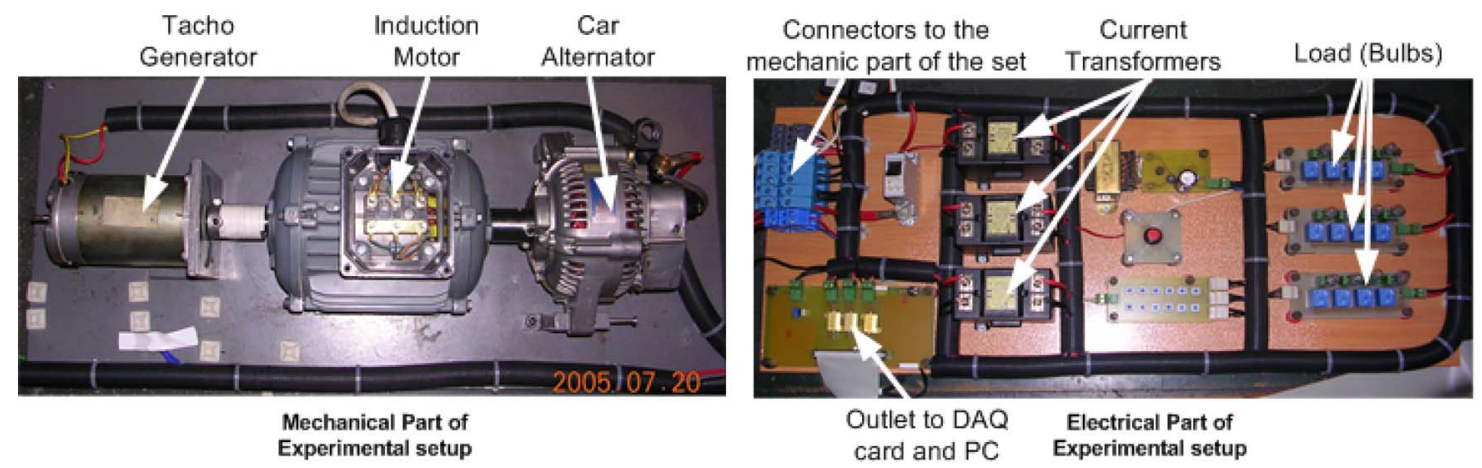

Fig. 5. Experimental setup.

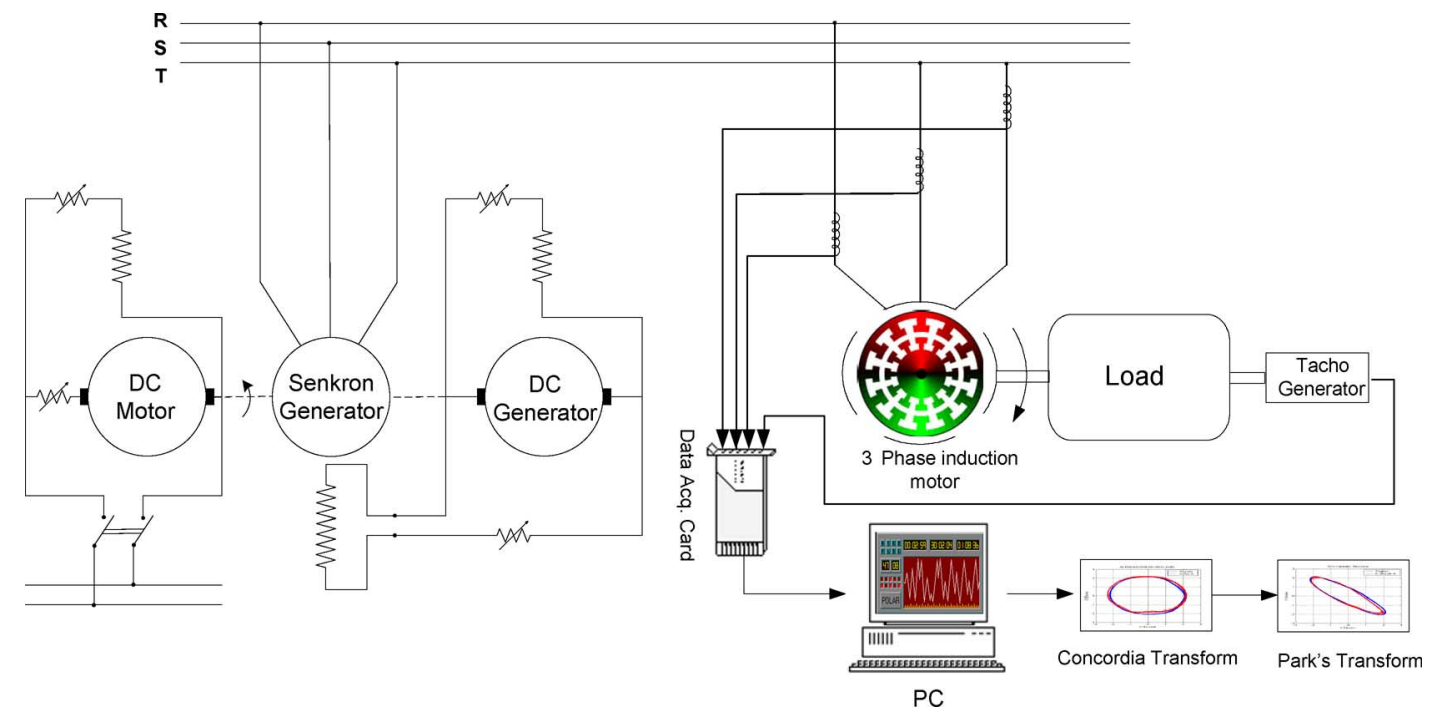

Fig. 6. Experimental test philosophy.

The occurrence of a bearing failure manifests itself in the deformation of the ellipse in the case of Park transform and in the deformation of the circle in the case of Concordia transform. These are very simple reference figures that allow the detection of abnormal conditions by monitoring the deviations of acquired patterns. In the following, they will be applied for the detection and the diagnosis of bearing failures.

\section{EXPERIMENTAL RESULTS}

\section{A. Test Facility Description}

Fig. 5 describes the experimental setup. It is composed of two parts: a mechanical part that has a tacho-generator, a three-phase squirrel cage induction motor, and a car alternator. The tacho-generator is a dc machine that generates $90 \mathrm{~V}$ at $3000 \mathrm{r} / \mathrm{min}$. It is used to measure the speed. It produces linear voltage between 2500 and $3000 \mathrm{r} / \mathrm{min}$. The alternator is a three-phase synchronous machine with a regulator and a rectifier circuit that stabilize the output voltage at $12 \mathrm{~V} \mathrm{dc}$. The advantage of using a car alternator instead of a dc generator is that constant output voltage is obtained at various speeds. The induction motor could be identically loaded at different speeds.

Moreover, if the induction motor is supplied from the network, motor current will have time and space harmonic components as well as bearing fault sourced harmonics. This makes it harder to determine the bearing failure effect on the stator current, and therefore, complicates the fault detection process. For these reasons, the induction motor is

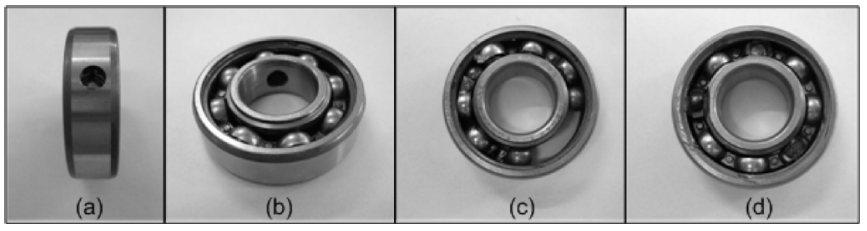

Fig. 7. Artificially deteriorated bearings. (a) Outer race deterioration. (b) Inner race deterioration. (c) Cage deterioration. (d) Ball deterioration.

fed by an alternator. In this way, supply harmonic effects are eliminated and only bearing failure effects could be observed on the stator current. Fig. 6 is then given to illustrate the experimental test philosophy.

The tested induction motor has the following rated parameters: 0.75 $\mathrm{kW}, 220 / 380 \mathrm{~V}, 1.95 / 3.4 \mathrm{~A}, 2780 \mathrm{r} / \mathrm{min}, 50 \mathrm{~Hz}, 2$ poles, Y-connected. It has two 6204.2ZR type bearings.

From the bearing data sheet, the following parameters are obtained: the outside diameter is $47 \mathrm{~mm}$ and inside one is $20 \mathrm{~mm}$. Assuming that the inner and the outer races have the same thickness gives the pitch diameter $D_{P}=31.85 \mathrm{~mm}$. The bearing has eight balls $(N=8)$ with an approximate diameter of $D_{B}=12 \mathrm{~mm}$ and a contact angle $\theta=0^{\circ}$. These bearings are made to fail in experiments by drilling holes of various radii with a diamond twist bit while controlling temperature by oil circulation. Some of the artificially deteriorated bearings are shown in Fig. 7. 

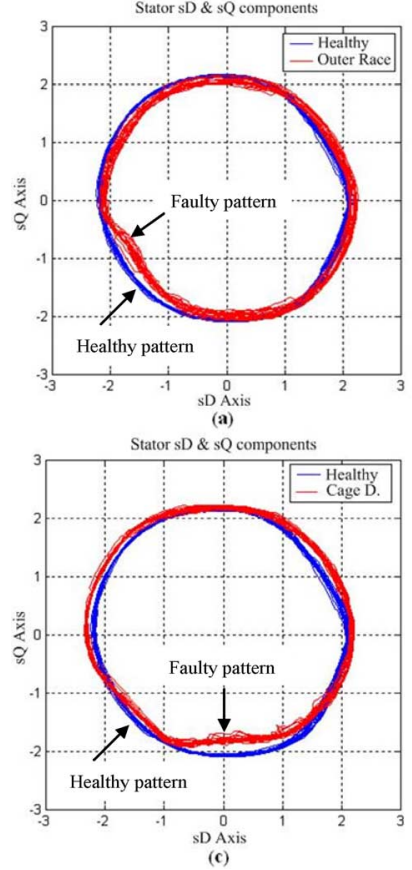

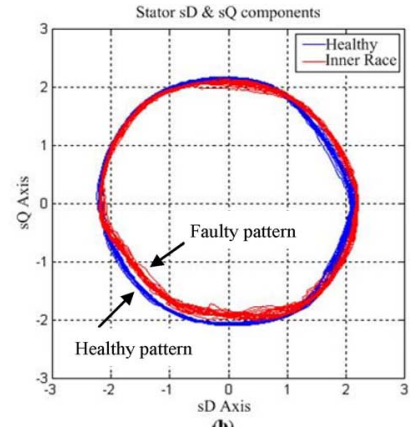

(b)

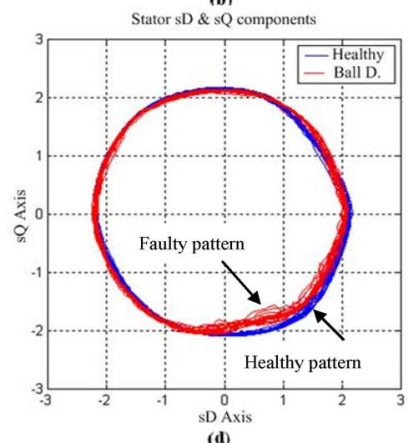

(d)
Fig. 8. Stator current $s D-s Q$ component trajectory comparison.
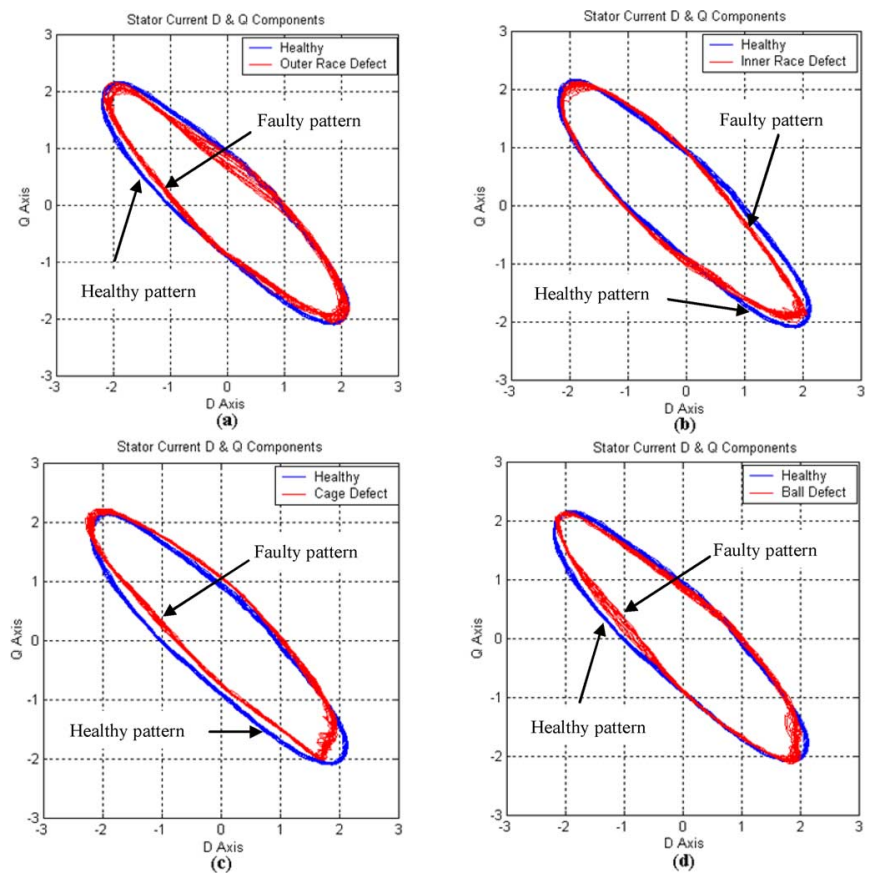

Fig. 9. Stator current $D-Q$ components trajectory comparison.

\section{B. Concordia Transform Experimental Results}

Sampling frequency is chosen as $10 \mathrm{kHz}$. All the data obtained are used to compute stator $s D-s Q$ and $D-Q$ components to obtain $s D-s Q$ (Concordia) and $D-Q$ (Park) patterns.

The induction motor was initially tested with healthy bearings in order to determine the reference current Concordia and Park patterns. Afterwards, it was tested with the different artificially deteriorated bearings. These experiments are summarized by Fig. 8 for Concordia patterns and by Fig. 9 for Park Patterns.

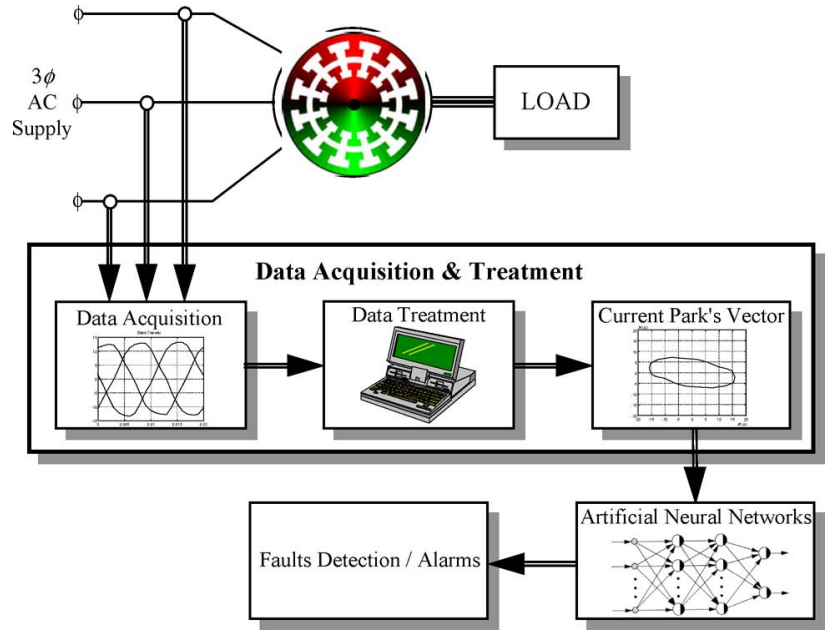

Fig. 10. Diagnosis process automation using neural networks [21].

It could be seen that bearing failures cause a clear deformation of the stator current $s D-s Q$ and $D-Q$ trajectories. Moreover, an insight analysis of Fig. 9 leads to an obvious classification of bearing failures according to a specific deformation of the initial ellipse: this clearly shows the diagnosis capability of the Park transform approach.

The fault detection and diagnosis process could be summarized as: the occurrence of a bearing failure manifests itself in the deformation of the current pattern corresponding to a healthy condition (failure detection). The deformation analysis will lead to the failure diagnosis. Therefore, according to the aforementioned experimental analysis, it seems that the Park transform approach has better diagnosis capabilities then the Concordia transform. However, the Park approach is speed sensor based, which is not the case of the Concordia approach. This drawback could be justified by the importance of bearing failure diagnosis as they account for approximately $50 \%$ of total failures in induction motors. Otherwise, sensorless fault detection and diagnosis should be performed as in [26], where the speed is estimated from the motor current rotor slot harmonic.

\section{Discussions}

The compared fault detection and diagnosis approaches will not be applied as visual inspection techniques. These approaches are indeed associated with techniques that automate the bearing failure detection and diagnosis. These techniques should take into account two relevant problems dealing for induction motor rotor failure detection: 1) timevarying load effect [27] and 2) incipient fault detection.

These two problems could be simply taken into account by using a sort of severity index [24]. Indeed, a severity index could address both the problems of fault detection in presence of an oscillating or position-varying load torque and incipient failures [28], [29].

Finally, it is obvious that the power supply quality will affect the pattern shape (e.g., hexagonal shape for a square-wave voltage supply) but the compared approaches that rely upon the difference between a healthy and a faulty pattern will still be valid.

\section{Detection And Diagnosis Process Automation}

Park and Concordia transform approaches should be associated with intelligent techniques that automate the process of bearing failure detection and diagnosis and take into account the aforementioned discussed 


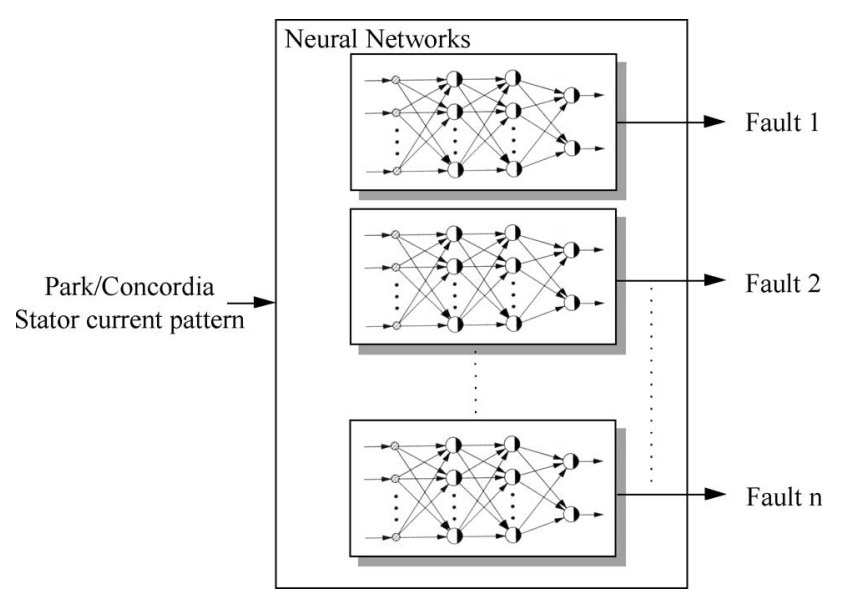

Fig. 11. Decentralized neural network diagnosis approach.

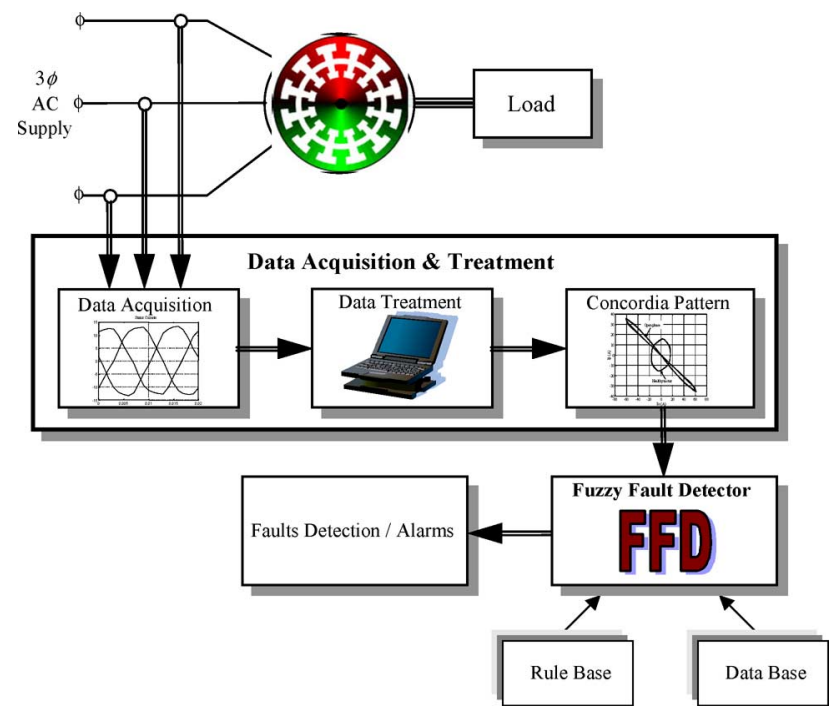

Fig. 12. Diagnosis process automation using fuzzy logic [24].

problems. For that purpose, two techniques are extensively used: neural networks [21], [25] and fuzzy logic [24], [30].

\section{A. Neural Networks}

Neural networks are used due to their numerous advantages. Indeed, when properly tuned, they could improve the diagnosis performance. They are easy to extend and modify, and they could be easily adapted by the incorporation of new data as it became available. For the analysis of stator current Park vector patterns, neural networks may be used as classifying systems. To perform classification, it is necessary to attach to each pattern a label that describes the operational state of the induction motor at the time of collecting the pattern. The input to the network is a pattern and the output is the class label.

For illustration, Fig. 10 shows a possible neural-network-based fault detection and diagnosis approach. In this case, the diagnosis process should be based on a decentralized approach, as illustrated by Fig. 11, to facilitate a satisfactory distributed implementation of new types of faults to the initial neural network system.

\section{B. Fuzzy Logic}

The main reason for choosing a fuzzy approach is the very nature of the changes in the attributes. It is nonlinear, and in addition, it would be unreasonable to expect that each time the same level of a particular fault arises, the attributes would measure exactly the same values. The boundaries between two levels of a certain fault or between two faults are not sharply defined, and therefore, the use of a classic true or false logic is inappropriate, whereas use of a fuzzy logic is highly justified.

For illustration, Fig. 12 shows a possible fuzzy-logic-based fault detection and diagnosis approach. It should be noted that implementation of new types of faults to the initial fuzzy fault detector is simply done by adding new fuzzy rules followed by an optimization process [29].

\section{CONCLUSION}

This paper dealt with the problem of bearing failure detection and diagnosis in induction motors. It compares two fault detection and diagnosis techniques, namely the Park transform approach and the Concordia transform. Experimental tests were carried out on a $0.75 \mathrm{~kW}$ two-pole induction motor with artificial bearing damage. These results seem to indicate that the Park transform approach has better diagnosis capabilities than the Concordia transform. However, the Park approach is speed sensor based, which is not the case of the Concordia approach. This drawback could be justified by the importance of bearing failure diagnosis as they account for approximately $50 \%$ of total failures in induction motors. Otherwise, sensorless fault detection and diagnosis should be performed using the Park transform approach as the speed could be estimated from the motor current rotor slot harmonic.

\section{REFERENCES}

[1] M. E. H. Benbouzid and G. B. Kliman, "What stator current processing based technique to use for induction motor rotor faults diagnosis?," IEEE Trans. Energy Convers., vol. 18, no. 2, pp. 238-244, Jun. 2003.

[2] T. Harris, Rolling Bearing Analysis. New York: Wiley, 2001.

[3] R. F. Schiferl and M. J. Melfi, "Bearing current remediation options," IEEE Ind. Appl. Mag., vol. 10, no. 4, pp. 40-50, Jul./Aug. 2004.

[4] N. Tandon and A. Choudhury, "A review of the vibration and acoustic measurement methods for detection of defects in rolling element bearings," Tribol. Int., vol. 32, no. 8, pp. 469-480, 1999.

[5] N. Tandon, G. S. Yadava, and K. M. Ramakrishna, "A comparison of some condition monitoring techniques for the detection of defects in induction motor ball bearings," Mech. Syst. Signal Process., vol. 21, no. 1, pp. 244-256, Jan. 2007.

[6] J. R. Stack, T. G. Habetler, and R. G. Harley, "Fault-signature modeling and detection of inner-race bearing faults," IEEE Trans. Ind. Appl., vol. 42, no. 1, pp. 61-68, Jan./Feb. 2006.

[7] J. R. Stack, R. G. Harley, and T. G. Habetler, "An amplitude modulation detector for fault diagnosis in rolling element bearings," IEEE Trans. Ind. Electron., vol. 51, no. 5, pp. 1097-1102, Oct. 2004.

[8] M. E. H. Benbouzid, "A review of induction motors signature analysis as a medium for faults detection," IEEE Trans. Ind. Electron., vol. 47, no. 5, pp. 984-993, Oct. 2000.

[9] J.-H. Jung, J.-J. Lee, and B.-H. Kwon, "Online diagnosis of induction motors using MCSA," IEEE Trans. Ind. Electron., vol. 53, no. 6, pp. 1842 1852, Dec. 2006.

[10] A. M. Knight and S. P. Bertani, "Mechanical fault detection in a mediumsized induction motor using stator current monitoring," IEEE Trans. Energy Convers., vol. 20, no. 4, pp. 753-760, Dec. 2005.

[11] J. Ilonen, J.-K. Kamarainen, T. Lindh, J. Ahola, H. Kalviainen, and J. Partanen, "Diagnosis tool for motor condition monitoring," IEEE Trans. Ind. Appl., vol. 41, no. 4, pp. 963-971, Jul./Aug. 2005.

[12] R. R. Schoen, T. G. Habetler, F. Kamran, and R. G. Bartfield, "Motor bearing damage detection using stator current monitoring," IEEE Trans. Ind. Appl., vol. 31, no. 6, pp. 1274-1279, Nov./Dec 1995.

[13] B. Yazici and G. B. Kliman, "An adaptive statistical time-frequency method for detection of broken bars and bearing faults in motors using stator current," IEEE Trans. Ind. Appl., vol. 35, no. 2, pp. 442-452, Mar./Apr 1999. 
[14] J. R. Stack, T. G. Habetler, and R. G. Harley, "Bearing fault detection via autoregressive stator current modeling,," IEEE Trans. Ind. Appl., vol. 40, no. 3, pp. 740-747, May/Jun. 2004.

[15] M. J. Devaney and L. Eren, "Detecting motor bearing faults," IEEE Instrum. Meas. Mag., vol. 7, no. 4, pp. 30-50, Dec. 2004.

[16] L. Eren and M. J. Devaney, "Bearing damage detection via wavelet packet decomposition of the stator current," IEEE Trans. Instrum. Meas., vol. 53, no. 2, pp. 431-436, Apr. 2004.

[17] C. Wang and R. X. Gao, "Wavelet transform with spectral post-processing for enhanced feature extraction," IEEE Trans. Instrum. Meas., vol. 52, no. 4, pp. 1296-1301, Aug. 2003.

[18] B. Li, M.-Y. Chow, Y. Tipsuwan, and J. C. Hung, "Neural-network based motor rolling bearing fault diagnosis," IEEE Trans. Ind. Electron., vol. 47, no. 5 , pp. $1060-1068$, Oct. 2000.

[19] M. S. Ballal, Z. J. Khan, H. M. Suryawanshi, and R. L. Sonolikar, "Adaptive neural fuzzy inference system for the detection of inter-turn insulation and bearing wear faults in induction motor," IEEE Trans. Ind. Electron. vol. 54, no. 1, pp. 250-258, Feb. 2007.

[20] S. M. A. Cruz and A. J. M. Cardoso, "Stator winding fault diagnosis in three-phase synchronous and asynchronous motors, by the extended Park's vector approach," IEEE Trans. Ind. Appl., vol. 37, no. 5, pp. 1227-1233, Sep./Oct. 2001.

[21] H. Nejjari and M. E. H. Benbouzid, "Monitoring and diagnosis of induction motors electrical faults using a current Park's vector pattern learning approach," IEEE Trans. Ind. Appl., vol. 36, no. 3, pp. 730-735, May/Jun. 2000.

[22] A. J. Marques Cardoso, S. M. A. Cruz, and D. S. B. Fonseca, "Interturn stator winding fault diagnosis in three-phase induction motors, by Park's vector approach,," IEEE Trans. Energy Convers., vol. 14, no. 3, pp. 595-598, Sep. 1999.
[23] J. L. H. Silva and A. J. M. Cardoso, "Bearing failures diagnosis in threephase induction motors by extended Park's vector approach," in Proc. IEEE IECON 2005, Raleigh, NC, Nov., pp. 2591-2596.

[24] F. Zidani, M. E. H. Benbouzid, D. Diallo, and M. S. Nait-Said, "Induction motor stator faults diagnosis by a current Concordia pattern based fuzzy decision system," IEEE Trans. Energy Convers., vol. 18, no. 4, pp. 469475, Dec. 2003.

[25] D. Diallo, M. E. H. Benbouzid, D. Hamad, and X. Pierre, "Fault detection and diagnosis in an induction machine drive: $\mathrm{A}$ pattern recognition approach based on Concordia stator mean current vector," IEEE Trans. Energy Convers., vol. 20, no. 3, pp. 512-519, Sep. 2005.

[26] K. Kim, A. G. Parlos, R. Mohan Bharadwaj, "Sensorless fault diagnosis of induction motors," IEEE Trans. Ind. Electron., vol. 50, no. 5, pp. 10381051, Oct. 2003.

[27] R. R. Schoen and T. G. Habetler, "Effects of time-varying loads on rotor fault detection in induction machines," IEEE Trans. Ind. Appl., vol. 31, no. 4, pp. 900-906, Jul./Aug. 1995.

[28] M. Y. Chow, B. Li, and G. Goddu, "Intelligent motor fault detection," in Intelligent Techniques in Industry, L. C. Jain, Ed. Boca Raton, FL: CRC Press, 1998.

[29] M. Y. Chow, Methodologies of Using Neural Network and Fuzzy Logic Technologies for Motor Incipient Fault Detection. Singapore: World Scientific, 1997.

[30] F. Zidani, D. Diallo, M. E. H. Benbouzid, and R. Nait-Said, "A fuzzybased approach for the diagnosis of fault modes in a voltage-fed PWM inverter induction motor drive," IEEE Trans. Ind. Electron., vol. 55, no. 2, pp. 586-593, Feb. 2008. 